\title{
EXPLORING THE SHORT TERM AND LONG TERM OUTCOMES OF A MEDICAL SCHOOL SUMMER PROGRAM FOR HIGH SCHOOL STUDENTS
}

\author{
Aihua Wang, Thesla Anderson and Helen Livingston Florida State University College of \\ Medicine
}

\section{AUTHOR NOTE}

Aihua Wang is a program evaluation specialist with the Student Advising and Outreach Office at the Florida State University College of Medicine in Tallahassee, Florida.

Thesla Anderson is the Director of the Office of Undergraduate Outreach and Advising at the Florida State University College of Medicine in Tallahassee, Florida.

Helen Livingston is the Associate Dean for Pre-College, Undergraduate, Graduate, and Student Research Programs at the Florida State University College of Medicine in Tallahassee, Florida.

Corresponding author: Aihua Wang _
Aihua.wang@med.fsu.edu
1115 West Call Street, Suite
2140 Tallahassee, FL, 32306
Fax: 850-644-5766
Telephone: $850-645-8700$

\begin{abstract}
The purpose of the study is to evaluate short-term and/or long-term impact of the Summer Institute at Florida State University College of Medicine on high school students who participated in the program between 2011 and 2014. The pre-test/post-test method was used to examine immediate program effects on students' knowledge and skills in medicine and science. Students were surveyed to collect their feedback about various program activities and components. In addition to these short-term outcomes, students were tracked to explore potential long-term outcomes related to college enrollment and choice of major. The results show that the post-test scores are higher than the pre-test scores, and the differences are statistically significant, which indicates that the program has helped increase students' knowledge and skills in science and medicine. The evaluation survey results also show positive feedback from the students about the program, particularly the hands-on activities and mentoring from medical students. Most of the high school graduates tracked and contacted have successfully entered college, and the majority of them chose certain majors related to science or medicine. In conclusion, the results imply that the program has made some positive short-term and long-term impact on the students participating in the program. The program model, based on the contextual learning theory, seems to be effective. However, the variance in students' ratings on program activities and the pre-test/post-test score differences suggest that the program needs to be fine-tuned in order to accommodate the different needs of the students from diverse backgrounds.
\end{abstract}

Keywords—outreach program; science education; evaluation research; high school 


\section{Introduction}

As the population of the United States becomes more ethnically and culturally diverse, there is still a lack of diversity within the medical school and physician workforce. African Americans, Hispanics and Native Americans account for about $29 \%$ of the total population in the U.S., but only $12 \%$ of practicing physicians, $15 \%$ of the medical school applicant pool, and 14\% of medical school matriculants (Association of American Medical Colleges, 2008 \& 2010; U.S. Census Bureau, 2010). In order to bring more diversity into medical schools and the physician workforce, various medical school pipeline programs have been established over the past several decades to target under-represented minority and rural students at pre-college, college, and post baccalaureate levels (Butler, 1999; Taylor, 1999).

Established in 2008, the Summer Institute (SI) program at the Florida State University College of Medicine (FSUCOM) is part of the nationwide effort to reach out to diverse high school students who have an expressed interest in medicine. The program is in line with the FSUCOM mission of training primary care physicians from under-represented minority groups to serve in rural and under-served areas. The SI program, which is a week-long residential program, specifically targets rising junior and senior high school students from rural and under-served areas and provides them with a variety of academic workshops and hands-on activities related to the medical field and college life. The purpose of this study is to examine the effectiveness of the SI program with multiple evaluation strategies to inspect whether the SI program has made any short-term or longterm impact on participants. We hope that by discussing the strengths and challenges of the SI program, this study can provide some useful lessons for other universities that offer similar summer programs in science or healthcare fields for rural and underrepresented minority students.

\section{Literature review}

Many medical schools sponsor summer programs for high school students that expose them to medical school, clinical settings, and college life. The lengths of these programs vary from one week to three years, and the participants include high school students only, a mixture of middle school and high school students, or a mixture of high school and college students. The contents of program are also different, ranging from hands-on research and lab projects to intensive academic study on certain science subjects to extensive career exploration of healthcare settings and professionals (Association of American Medical Colleges, 2009).

Despite the variety of summer programs for high school students in the area of medicine, there are only a limited number of published studies about these programs. For the purpose of this study, we had to expand the scope of literature review to include studies of summer programs related to other science and healthcare professions, e.g., nursing. Most of the published studies are of a descriptive nature and examined outcomes such as participants' academic achievement, their college enrollment, and choices of major or career (Bumgarner, Means, \& Ford, 2003; Calkins, 1983; Cluskey, Jackson, \& Brubaker, 2006; Helm, Paker, \& Russell 1999; Lewis, 1996; Mares \& Calkins, 1987; Marshall, 1975; Rohrbaugh \& Corces, 2011; Thurmond \& Mott, 1990). A few studies surveyed participants about their program experiences and included the feedback from participants (Cluskey, Jackson, \& 
Brubaker, 2006; Gormley, 2009; Mares \& Calkins, 1987; Niemann, Miller, \& Davis, 2004; Rohrbaugh \& Corces, 2011). These studies generally showed positive outcomes including participants' high rates of admission into colleges, popular choices of majors related to medicine and science, and favorable feedback about the programs.

Although these studies provide important information about program design, implementation, and certain long-term outcomes at the post-secondary level, they lack empirical rigor and neglect to examine short-term program outcomes. Only a few studies adopted empirical research techniques such as pre-test and post-test design and explore immediate program impact on students. With various outcomes such as knowledge about science or attitudes towards certain healthcare professions, these empirical studies yielded mixed results. For example, one study on a summer cancer research program compared student expectations of the program before participation (the pre-test) with their selfreported program outcomes after participation (the post-test) and found no significant differences (Cookfarira, Zevon, \& Mirand, 1987). Another study on a science enrichment program for gifted high school students also failed to demonstrate any significant difference in participants' attitudes towards science between the pretest and post-test (Stake \& Mares, 2001). However, one study about a summer nursing camp showed positive change in participants' attitude towards a nursing career after the camp (Yeager \& Cheerer, 2007), and another study about a science enrichment program demonstrated an increase in the students' knowledge of biology and chemistry as well as their interests in pursuing science after they participated in the program (Sikes \& Schwartz-Bloom, 2009). On a whole, more rigorous evaluation studies with empirical designs are needed to examine the effectiveness of summer programs as an important strategy to diversify professionals in medicine, science and healthcare.

This study seeks to contribute to the current literature by adopting comprehensive evaluation strategies to examine both short-term and long-term program outcomes through pre-test and post-test surveys, activity evaluation surveys, and phone interviews. It is hoped that this study can help address the issue of the lack of rigorous evaluation studies and conclusive findings about the effectiveness of summer programs that are being offered to many high school students. In addition, the SI program was designed to reach more students with multiple short-sessions, so it is important to explore whether short programs like the SI can also have an impact on students compared to many other typical summer programs with longer sessions.

\section{Research methods}

The SI program is a week-long program that includes physician shadowing, a service learning project, bio-medical labs, a visit to the anatomy lab to view dissected learning stations, test preparation for the SAT, pre-medical advising, group research projects, and college-preparatory workshops. The activities are organized each day around a theme. These themes include Geriatrics Day, Primary Care Day, Rural Medicine Day, Medical School Day, Research and Physician Shadowing Day. A few social activities are also provided in order to facilitate a connection among students and to provide relaxation. Five or six medical school students are selected for each session to serve as facilitators and mentors for the students. They supervise students' 
activities, facilitate their research projects, provide presentations on health care disparities and other health-related topics, and answer student questions about medical student life and healthcare careers. Their mentoring can expose the SI students to first-hand experiences with the life of a medical student.

In order to evaluate short-term outcomes, surveys were administered to the students at the end of each day to gather their feedback about specific activities and workshops on a 5-point Likert scale (1=not helpful at all and 5=very helpful). Pre-test and post-test surveys were also administered to them in order to capture the potential impact that the SI program may have had on students' perceived knowledge and skills related to medicine and science. The students were asked to indicate on a 5point scale whether they believed they possessed these relevant skills or knowledge $(1=$ strongly disagree, and $5=$ strongly agree). The pre-test survey was administered during the orientation at the very beginning of the program, and the post-test survey was administered at the end of the program.

If the desired short-term outcome of the SI program is to increase students' knowledge and interest in medicine and science and expose them to college and medical school life at an early stage, some long-term outcomes may include the students' admission into colleges and their choices of majors. In order to gather the information in this regard, all the SI alumni who have graduated from high schools by 2014 were tracked through phone calls. For those students who did not answer the phone calls, the FSU registrar database was used to determine whether they have entered FSU and if so, what major(s) they chose.

\section{Results \\ 4.1 Pre-test and Post -test Results}

Between 2011 and 2014, 241 students participated in the SI and 239 students took part in the pre-test and post-test ${ }^{1}$. $72 \%$ of the SI students were female and $28 \%$ of them were male. In terms of race and ethnicity, $43 \%$ of them were White, $27 \%$ were Black, $17 \%$ were Hispanic and $8 \%$ were Asian. Almost a third of them $(26 \%)$ came from rural counties, and about one fifth of them (18\%) were from low-income families (with annual income being $\$ 24,999$ or less).

In analysis, the pre-test and post-test questions were grouped into 10 themes based on the activity and workshop topics. They include clinic skills, labs, physician shadowing, geriatrics, rural health, cultural diversity, medical informatics, anatomy, group research and presentation project, and college and medical school preparation. A paired sample t-test was conducted for each of the themes as well as the total average. The t-test results are summarized in Table 1 below.

\footnotetext{
${ }^{1}$ The study was not initiated until 2011 although program was established in 2008.
} 
Table 1. FSU COM Summer Institute pre-test and post-test comparison 2011-2014

\begin{tabular}{|l|l|l|l|l|l|}
\hline Activity Theme & $\begin{array}{l}\text { Pre } \\
\text { Test } \\
\text { Mean }\end{array}$ & $\begin{array}{l}\text { Std. } \\
\text { Deviation }\end{array}$ & $\begin{array}{l}\text { Post } \\
\text { Test } \\
\text { Mean }\end{array}$ & $\begin{array}{l}\text { Std. } \\
\text { Deviation }\end{array}$ & $\begin{array}{l}\text { Mean Difference } \\
\text { (Post Test - Pre } \\
\text { Test) }\end{array}$ \\
\hline Clinic Skill & 3.35 & 0.80 & 4.74 & 0.39 & $1.39 * *$ \\
\hline Lab & 2.79 & 0.80 & 4.56 & 0.52 & $1.77 * *$ \\
\hline $\begin{array}{l}\text { Physician } \\
\text { Shadowing }\end{array}$ & 3.41 & 0.87 & 4.75 & 0.41 & $1.34 * *$ \\
\hline Geriatrics & 3.04 & 0.68 & 4.68 & 0.45 & $1.64 * *$ \\
\hline Rural Health & 2.89 & 0.97 & 4.82 & 0.36 & $1.93^{* *}$ \\
\hline Cultural Diversity & 3.36 & 0.99 & 4.62 & 0.63 & $1.26^{* *}$ \\
\hline Medical Informatics & 3.14 & 0.81 & 4.64 & 0.58 & $1.50^{* *}$ \\
\hline Anatomy & 2.41 & 1.07 & 4.81 & 0.39 & $2.40^{* *}$ \\
\hline Group Research and & 4.13 & 0.64 & 4.80 & 0.40 & $0.67 * *$ \\
\hline Presentation Project & & & & & \\
\hline College and Medical & 3.36 & 0.75 & 4.74 & 0.41 & $1.38 * *$ \\
\hline School Preparation & & & & & \\
\hline Total & 3.18 & 0.51 & 4.72 & 0.29 & $1.54^{* *}$ \\
\hline$* * p<.01$. & & & & & \\
\hline & & & & & \\
\hline
\end{tabular}

The table shows that student post-test scores are higher than pre-test scores on overall and each of the program themes, and the differences are statistically significant $(\mathrm{p}<0.01)$. The total average post test score is 4.72 , which is 1.54 points higher than the total average pre-test score of 3.18. To better interpret the numbers with the survey scale, they indicate that the students in general stayed around "neutral" in self-assessing whether they possess the knowledge and skills asked in the pre-test, but leaned towards "strongly agree" in the post-test. It means that in general, the students perceived themselves to have more knowledge and skills in medicine, science and college/medical school preparation after their participation in the SI program.

With a closer look, we can see that the score differences between the pre-test and post-test vary among different types of activities. Those activities related to labs, anatomy and rural health had the highest gains between the pre-test and post-test scores, particularly the anatomy lab. Students generally did not believe that they possess the knowledge and skills in these areas before the program (the pre-test mean scores ranging from 2.41-2.89); but after participating in the activities, they either agreed or strongly agreed that they had good understanding in these areas (the post-test mean scores ranging from 4.564.82). In contrast, the group research and presentation project had the lowest gain of scores between the pre-test and post-test. It seems that students believed they had already known how to undertake group research and presentation project before participation in the SI (with a pre-test mean score of 4.13). Even though its posttest mean score (4.80) is still higher with statistical significance, the actual increase is not as much as the one in other activities like labs or anatomy.

\subsection{Evaluation Survey Results}

In addition to the pre-test and post-test, a Copyright (C) 2015, Knowledge Enterprises Incorporated. All rights reserved. 
short survey was also administered to all the students on a daily basis to collect their opinions about specific activities and workshops provided each day. Out of the 241 participating students, 227 completed the surveys. The results show that the majority of the students thought that the SI was helpful. Specifically, 169 students (74\%) believed it helped them "a lot" to be better prepared for entering college, and 194 students (85\%) thought it helped "a lot" to increase their knowledge about the medical field.

The majority of participating students gave positive feedback about program activities and workshops. On average, $86 \%$ of the students agreed that the activities and workshops were "helpful" or "very helpful". The percentages of students who gave positive ratings vary to some degree by different activities, ranging from $60 \%$ to $99 \%$. The variance seems to be partially related to the types of activities. The ones with relatively lower percentages of students (below $80 \%$ ) giving positive ratings mostly include lecturing workshops while the ones to which more students (above 90\%) gave favorable ratings are mostly handson activities such as the Vital Signs Workshop, Anatomy, Lab, and Training in Clinical Skills \& Simulation Center.

Mentors are another important aspect of the SI program. Based on the survey results, the majority of the students enjoyed interacting with the mentors. They reported that the mentors were friendly, welcoming and supportive. Specifically, they appreciated the experiences and insights that the mentors shared with them about studying in colleges and medical schools. One student said, "The mentors were more involved than any other camp I have been to. It was cool that they were medical students. It showed me what my goals were and they served as role models". Another student commented, "They (the mentors) did not treat me as a student to watch over, but as a person who wishes to follow (in) their footsteps". Students' positive feedback shows that choosing medical students as mentors has proved to be an effective model of the SI program.

\subsection{Postsecondary Outcomes}

Since one of the purposes of the SI program is to facilitate students' matriculation into colleges, and eventually into medical schools, the program office has been tracking the students consistently. Out of the 241 participating students between 2011 and 2014, 153 students had graduated from high school by 2014. The SI staff was able to contact 123 of these graduates, while 30 graduates were unreachable. Out of the 123 students whom were tracked, 122 (99\%) successfully entered colleges and 99 of them $(81 \%)$ chose a major related to science or a healthcare profession.

\section{Discussion and Conclusion}

On the whole, the Summer Institute at FSU College of Medicine seems to be successful. According to the evaluation survey results, the majority of the students thought that the program was beneficial. The pre-test and post-test also showed that the program helped increase the students' knowledge and skills in medicine, science and preparation for colleges and medical schools. The students' interaction with the medical school students also contributed to their positive experience with the program. Most of the high school graduates whom the program office was able to track were 
successfully admitted into colleges and chose majors related to science or medicine.

The program design is based on the contextual learning theory (Imel, 2000), which asserts that real learning happens in the realm of the actual practice world within a community. Originated from the constructivist theory, the contextual learning theory argues that effective learning takes place when an individual constructs meaning through interacting with people, situations, or environments which are meaningful to them (Imel, 2000). Most of the SI activities put students into various authentic learning contexts, i.e., hospitals, research labs, assisted living facilities for seniors, rural clinics, and a medical school/college campus. Students were also given the opportunity to interact with medical school students, faculty members, healthcare professionals and patients. The students' high ratings on the activities and on their interactions with mentors, as well as the significant increase between the pre-test and post-test, imply that the contextual learning model adopted by the SI program is effective.

It is worth noting that student feedback varies to a certain degree by different themes and types of activities. The results seem to imply that students may prefer the activities which can bring them both new and real-world experiences, such as research lab and anatomy. Variances in student ratings suggest that it is important for the program staff to achieve a balance in providing the activities that are informative, educational and interesting. Consideration may be given to replace those activities, i.e., group research and a presentation project with high pre-test scores (which means the students already possessed sufficient knowledge and skills prior to their participation in the program). Carefully choosing the most effective activities can be crucial to the program's success, particularly considering that this week-long program is already shorter than similar summer programs offered by most other medical schools or universities.

Another possible source for the variance in student evaluation might be the difference in students' backgrounds. As the student demographic data indicate, the SI students are diverse in race and ethnicity, family income, schools and residence locations. All these background factors might influence student experience with the program. For instance, it is possible that the underrepresented minority students (Blacks, Hispanics and Native Americans) from low-performing schools may have lower self-assessments of science and medicine knowledge before they start the SI program than the non-minority students from high-achieving schools. Therefore, the score difference between pre-test and post-test may be greater for the students with a disadvantaged background. In fact, our data have shown that the underrepresented minority students had lower pre-test score than the students from the other racial groups in labs $(\mathrm{MD}=.24$, SEM $=.10, p=.02$ ) and lower post-test scores in physician shadowing $(\mathrm{MD}=.11$, $\mathrm{SEM}=.053, p=.04)$, geriatrics $(\mathrm{MD}=$ $.17, \mathrm{SEM}=.059, p=.004)$, labs $(\mathrm{MD}=$ $.14, \mathrm{SEM}=.07, p=.045)$, anatomy $(\mathrm{MD}=$ $.21, \mathrm{SEM}=.054, p=.0001)$ and group research and presentation project $(\mathrm{MD}=$ $.11, \mathrm{SEM}=.054, p=.041)$. Likewise, students from rural areas also showed lower pre-test scores than the non-rural students in geriatrics $(\mathrm{MD}=.27, \mathrm{SEM}=$ $.10, p=.009)$ and anatomy $(\mathrm{MD}=.38$, $\mathrm{SEM}=.14, p=.009)$, and lower post-test scores in labs $(\mathrm{MD}=.18 \mathrm{SEM}=.08, p=$ $.02)$ and anatomy $(\mathrm{MD}=.21, \mathrm{SEM}=.07$, $p=.003)$. These are just preliminary 
results based on simple comparison of means. In our future study, we will use a larger sample and adopt a more advanced statistic technique like regression model in order to explore how various factors such as race, gender, residence location, family incomes and high school attended may potentially influence the student experience with the SI program as indicated by the difference between the pre-test and post-test scores. If factors of student backgrounds are proved to have some influence, then the program staff and manager may need to take the diversity factor into consideration when designing the program and look into the possibility of dividing students into subgroups for different activities to better suit their individual needs. Meanwhile, the program manager can also try to utilize the diversity as a resource and design group activities that can encourage students to explore and embrace the diversities among them, since studies have increasingly shown that interaction with diverse groups can benefit a student's personal growth, sense of purpose, and problem solving ability (Association of American Medical Colleges, 2008 \& 2010; Taylor, 1999).

In addition to customizing the program activities, a suggestion has been made that the SI program make extra efforts to recruit students from rural and disadvantaged backgrounds. Although half of the students come from underrepresented minority groups, only $26 \%$ and $18 \%$ of the students come from rural counties and low-income families respectively. Since the ultimate mission of the SI program and the hosting medical school is to recruit and train primary care physicians from under-represented minority groups to serve in rural and under-served areas, the program can play an important role in fulfilling the mission by targeting more students from rural areas and disadvantaged backgrounds.

Despite the authors' efforts to design and conduct a comprehensive program evaluation, this study still suffers some limitations. First of all, the data collected through pre-test and post-test surveys are self-reported, which may lead to inaccuracies due to students' potential subjectivity and bias. In the future, we will administer a more objective assessment in addition to the survey, which directly assesses specific knowledge and skills that the students are expected to master at the end of the SI activities and workshops. The assessment and the survey together can make the pre-test and post-test comparison more valid. Second, although the postsecondary outcomes of the SI participating students seem positive, it can be further consolidated by including a comparison groups of non-participating students and examining whether the college enrollment rate and the likelihood to choose a science or healthcare related major is higher for the SI participants than the non-participants.

In summary, this study has shown some strengths and challenges of the SI program. On one hand, the program used authentic learning and mentoring models, which has proved to be effective in providing informative and meaningful experiences to students. The hosting university has also provided valuable facilities, human resources, and financial support that is crucial to the program's success. On the other hand, students' varied feedback on different typesof program activities implies the challenge to provide a balanced mixture of informative lectures and hands-on activities within a short, one-week period of time. While trying to recruit more diverse students to fulfill its mission, the program also has to address 
the potential issue of how to customize the program to better accommodate different students' learning needs, particularly the students from disadvantaged backgrounds, and using the group diversity at the same time as a positive tool for students to explore and learn from each other's differences. 


\section{REFERENCES}

Association of American Medical Colleges. (2008). Diversity in Medical Education: Facts \& Figures 2008. Washington, DC: Association of American Medical Colleges.

Association of American Medical Colleges. (2009). Minority Student Opportunities in United States Medical Schools. Washington, DC: Association of American Medical Colleges.

Association of American Medical Colleges. (2010). Diversity in the Physician Workforce: Facts and Figures 2010. Washington, DC: Association of American Medical Colleges.

Bumgarner, S., Means, B., \& Ford, M. (2003). Building bridges from high school to healthcare professional. Journal for Nurses in Staff Development, 19(1), 18-22.

Butler, W. (1999). Project 3000 by 2000: Progress during tumultuous times. Academic Medicine, 74(4), 308-309.

Calkins, V. (58). A summer program to prepare high school students for careers in the health science. Journal of Medical Education, 1(69), 70.

Castro, G., Bouldin, P. A., Farver, D. W., Maugans, L. A., Sanders, L. C., \& Booker, J. (1999). The InterCon network: A program for education partnerships at the University of Texas-Houston Health Science Center. Academic Medicine, 74(4), 363-365.

Cluskey, M., Jackson, J. E., \& Brubaker, C. (2006). A university model for recruiting high school students to nursing. Nursing Education Perspectives, 27(6), 324-326.

Cookfaira, D., Zevon, M. A., \& Mirand, E. A. (1987). The use of goal attainment scaling to evaluate a cancer research training program for high school college students. Journal of Cancer Education, 1(4), 255-263.
Cregler, L. (1993). Enrichment programs to create a pipeline to biomedical science careers.

\section{Journal of Association for Academic} Minority Physicians, 4(4), 127-131.

Greenhalgh, T., Russell, J., Boynton, P., Lefford, F., Chopra, N., \& Dunkley, L. (2006). We were treated like adults, development of a pre-medicine summer school for 16 year olds from deprived socioeconomic backgrounds: Action research study. British Medical Journal, 332,762 .

Greenhalgh, T., Seyan, K., \& Boynton, P. (2004). Not a university type: Focus group study of social class, ethnic, and sex differences in school pupils' perceptions about medical school. British Medical Journal, 328, 1541.

Gormley, D. K., Frerick, J. A., \& Dean, A. (2009). Pathways to nursing: An innovative program to encourage high school students to enter nursing. Kentucky Nurse, 57(4), 7-8.

Helm, E., Parker, J. E., \& Russell, M. C. (1999). Education and career paths of LSU's summer science program students from 1985 to 1997 . Academic Medicine, 74(4), 336-338.

Imel, S. (2000). Contextual learning in adult education. Practice Application Brief No.12. Retrieved from http://www.ydae.purdue.edu/lct/hbcu/doc uments/ContextualLearninginAdu ltEducation.pdf.

Knox, K., Moynihan, J. A., \& Markowitz, D. G. (2003). Evaluation of short-term impact of a high school summer science program on students perceived knowledge and skills. Journal of Science Education and Technology, 12(4), 471-478.

Lewis, C. (1996). A state university's model program to increase the number of its disadvantaged students who matriculate into health professions. Academic Medicine, 71(10), 1050-1057. 
Little, D., Izutsu, S., Judd, N., \& Else, I. (1999). A medical school based program to encourage native Hawaiians to choose medical careers. Academic Medicine, 74(4), 339-341.

Mares, K., \& Calkins, V. (1987). Preparing high school students for a career in the health sciences. Journal of the National Medical Association, 79(2), 223-226.

Markowitz, D. G. (2004). Evaluation of longterm impact of a university high school summer science program on students' interest and perceived abilities in science. Journal of Science Education and Technology, 13(3), 395-407.

Marshall, E. (1975). An experiment in health careers recruitment: A summer program at Indiana University. Journal of the American Optometric Association, 46(12), 1284-1282.

Niemann, M., Miller, M. L., \& Davis, T. (2004). The University of Alabama at Birmingham Center of Community Outreach Development Summer Science Institute Program: A 3-year laboratory research experience for inner-city secondary-level students. Cell Biology Education, 3(3), 162180.

Rohrbaugh, M., \& Corces, V. G. (2011). Opening pathways for underrepresented high school students to biomedical research careers: The Emory University RISE program. Genetic Society of America, 189, 1135-1143.

Rye, J., \& Chester, A. L. (1999). WVU-community partnership that provides science and math enrichment for underrepresented high school students. Academic Medicine, 74(4), 352-354.

Sikes, S., \& Schwartz-Bloom, R. D. (2009). A science enrichment program for high school students. Biochemistry and Molecular Biology Education, 37(2), 77-83.

Srinivasan, A., Brown, J., Fahmy, N., Heitman, E., Singh, M., Szklo, M., . . . White, W. (2006). Preparing African Americans for careers in health care: The Jackson Heart Study. Ethnicity \& Disease, 16(3), 623-627. enrichment programs for gifted high school girls and boys: Predictors of program impact on science confidence and motivation. Journal of Research in Science Teaching, 38(10), 1065-1088.

Stake, J., \& Mares, K. (2005). Evaluating the impact of science-enrichment programs on adolescents science motivation and confidence: The splashdown effect. Journal of Research in Science Teaching, 42(4), 359375.

Taylor, V. (1999). The needs of students from diverse cultures. Academic Medicine, 74(4), 302-304.

The U.S. Census Bureau. (2010). 2010

Census Briefs. Retrieved from

http://www.census.gov

/2010census/news/press-

kits/briefs/briefs.html.

Thurmond, V., \& Cregler, L. (1999). Why students drop out of the pipeline to health professions careers: A follow-up of gifted minority high school students. Academic Medicine, 74(4), 448-451.

Thurmond, V., \& Mott, A. (1990). Minority students' career choices and education five years after they completed a summer enrichment program. Academic Medicine, 65(7), 478-479.

Winkleby, M. (2007). The Stanford Medical Youth Science Program: 18 years of a biomedical program for low-income high school students. Academic Medicine, 82(2), 139-145.

Winkleby, M., Ned, J., Ahn, D., Koehler, A., \& Kennedy, J. D. (2009). Increasing diversity in science and health professions: A 21-year longitudinal study documenting college and career success. Journal of Science Education and Technology, 18, 535-545.

Yeager, S., \& Cheever, K. H. (2007). A residential nursing camp program: Effects on adolescent attitudes toward nursing careers. Journal of Nursing Education, 46(10), 452-458.

Stake, J., \& Mares, K. (2001). Science 